\title{
DESAFIOS E OPORTUNIDADES DA LOGÍSTICA REVERSA DE ELETROELETRÔNICOS EM UMA OPERADORA DE CELULAR NA VISÃO DE GESTORES E USUÁRIOS
}

\author{
Carmem Silva Petito \\ carmem.petito3@gmail.com \\ Centro Universitário Metodista - IPA - RS / Brasil
}

\section{RESUMO}

O Brasil é um país com elevado consumo de eletroeletrônicos, particularmente os celulares, diante disto, há a necessidade do consumidor ter o conhecimento do descarte correto. Com a implantação da logística reversa, prevista na Política Nacional de Resíduos Sólidos, além das possibilidades de reaproveitamento e redução do consumo de novos insumos, pode ser evitatada a contaminação no meio ambiente, pois esses aparelhos contém metais pesados que são prejudiciais a saúde e ao meio ambiente. Perante o progresso tecnológico, consumo excessivo de aparelhos celulares e a obsolescência programada, esta pesquisa objetivou demonstrar a importância da logística reversa como instrumento de desenvolvimento econômico e social, caracterizado por um conjunto de ações, como o planejamento e controle do fluxo e custo efetivo de um produto até seu destino final em uma operadora de celular. Para a consecução deste trabalho foi realizada pesquisa qualitativa e quantitativa sendo necessária, respectivamente a colaboração do gestor da empresa pesquisada e de um grupo de usuários de telefone celular onde foram abordados os desafios e oportunidade da gestão da logística reversa e o conhecimento dos usuários sobre o descarte adequado. Foi realizado um breve questionário com os colaboradores de cinco lojas, sendo possível identificar o conhecimento dos mesmos sobre o tema abordado, somado a observação sistemática em lojas da operadora pesquisada. Os resultados trouxeram as vantagens ambientais como fator mais importante nas práticas de logística reversa, reduzindo o passivo ambiental deixado pelo ser humano, no grupo 
de usuário foi destacado a motivação e período da troca de aparelhos, que são baseados pelo avanço tecnológico e o desconhecimento sobre o que fazer com aparelhos inutilizados após a troca, contrastando com os resultados da observação sistemática nas lojas onde foi possível verificar aparelhos descartados nos locais apropriados.

PALAVRAS- CHAVE: Gestão da logística reversa. Resíduos eletroeletrônicos. Telefones celulares.

\section{ABSTRACT}

Brazil is a country with high consumption of electronics, particularly cell phones, because of this, there is a need for the consumer to be aware of the correct disposal. With the implementation of reverse logistics, as foreseen in the National Solid Waste Policy, besides the possibility of reuse and reduction of the consumption of new inputs, contamination in the environment can be avoided, since these devices contain heavy metals that are harmful to health and the environment. environment. In the face of technological progress, excessive consumption of cellular devices and programmed obsolescence, this research aimed to demonstrate the importance of reverse logistics as an instrument of economic and social development, characterized by a set of actions, such as planning and controlling the flow and cost effective of A product to its final destination in a cellular carrier. In order to achieve this work, a qualitative and quantitative research was carried out. The collaboration of the manager of the researched company and of a group of cellular phone users, where the challenges and opportunities of reverse logistics management and the users Disposal. A brief questionnaire was carried out with the employees of five stores, and it was possible to identify their knowledge about the subject matter, in addition to systematic observation in stores of the surveyed operator. The results brought the environmental advantages as the most important factor in the reverse logistics practices, reducing the environmental liability left by the human being, in the user group was highlighted the motivation and period of the exchange of devices, which are based on the technological advance and the lack of knowledge about What to do with unused appliances after the exchange, in contrast to the results of systematic observation in the stores where it was possible to check discarded devices in the appropriate places.

KEYWORDS: Reverse logistics management. Waste electrical and electronic. Mobile phones. 


\section{INTRODUÇÃO}

As novas tecnologias de comunicação provocam profundas modificações na vida dos indivíduos e das organizações, colaborando para modificar o mundo. A tecnologia, quando bem utilizada, diminui distâncias físicas e sociais, através da educação, da informação e até mesmo na esfera política, como destaca Egler (2010). O principal equipamento responsável por esta ampla e, em geral democrática, acessibilidade é o telefone celular. De acordo com dados da Inteligência em Telecomunicações (TELECO, 2016) no Brasil existem mais de 280 milhões de celulares ativos frente a uma população com mais de 204 milhões de pessoas, de acordo com o Instituto Brasileiro de Geografia e Estatística (IBGE, 2010)

A logística reversa tem como proposta o planejamento e controle do fluxo e custo efetivo de um produto até seu destino final. Seu objetivo é recuperar o valor dos bem e redução na utilização de matéria-prima (PEREIRA et al., 2012). Leite (2009) complementa, expondo que a logística reversa, torna possível o reaproveitamento de materiais, agregando valor econômico, ecológico e legal aos mesmos.

Atualmente a logística reversa tem amparo legal, através da Política Nacional de Resíduos Sólidos (PNRS), que faz com que as empresas e consumidores se tornem responsáveis pelo produto até o final de sua vida útil, intensificando o encaminhamento ambientalmente adequado (BRASIL, 2010). A PNRS define padrões sustentáveis de produção e consumo, procurando atender as necessidades atuais e estabelecer comprometimento com a qualidade ambiental.

Tem se observado o interesse das empresas sobre a logística reversa, onde, inicialmente a importância se dava por questões ambientais, preocupações com o meio ambiente e reciclagem. Com o passar do tempo, razões econômicas delimitadas pela competição e pelo marketing elevaram o 
envolvimento das empresas com a logística reversa. A partir daí ampliaram-se as oportunidades de redução de custos e negócios rentáveis.

Frente ao exposto, esta pesquisa objetivou identificar os desafios e oportunidades da gestão da logística reversa de eletroeletrônicos em uma empresa operadora de celular. Para alcançar tal objetivo, se buscou primeiramente, identificar como ocorre a gestão dos resíduos eletroeletrônicos na organização pesquisada e verificar as vantagens ambientais e econômicas da logística reversa dos resíduos eletroeletrônicos para uma empresa operadora de celular. Não foi esquecida uma parte fundamental da cadeia reversa: o consumidor, para a tender a este ponto se buscou identificar a atitude de um grupo de usuários de celular com relação ao descarte consciente de aparelhos telefônicos usados.

\section{REFERENCIAL TEÓRICO}

A gestão ambiental, de acordo com Alencastro (2012), é a maneira com a qual o Estado e as empresas se mobilizam pela conquista da qualidade ambiental, adotando práticas que garantam a conservação e preservação da biodiversidade; a redução do impacto ambiental; a reciclagem e cautela no uso de recursos naturais.

As empresas dos mais variados segmentos estão cada vez mais preocupadas e engajadas em alcançar um funcionamento ambiental correto, controlando e minimizando os impactos gerados em suas atividades. Este propósito empresarial está relacionado ao lucro, que se dá através do reaproveitamento de matéria prima, economia com água, luz e demais insumos necessários à produção, reduzindo os custos com insumos, através do reaproveitamento adequado, é possível gerar menor poluição e elevar o nível de competitividade perante a 
concorrência (SEBRAE, 2012). Sobre este tema Xavier e Correa (2013), destacam que:

a opção por não incluir negócios ambientalmente sustentáveis na visão estratégica da empresa parece não ser a melhor alternativa, uma vez que, no médio e longo prazo, a competição só tende a aumentar e a sustentabilidade, cada vez mais, configura-se, não apenas como uma fonte potencial de vantagem competitiva, mas também um promissor mecanismo de redução de custos (XAVIER; CORREA, 2013, p. 133).

Seguindo estes preceitos, as empresas vêm adotando modelos de gestão sustentáveis, impulsionadas pelo novo contexto mundial, resultando em uma alternativa cada vez mais usual na esfera empresarial. Investir em sustentabilidade é uma maneira de colaborar para a longevidade do negócio. (ZANBON; RICCO, 2009). Carvalho e Xavier (2014), ainda evidenciam a importância de se estabelecer um planejamento no mapeamento da gestão de resíduo, enfatizando que a gestão da cadeia reversa de resíduos, em particular dos tecnológicos, é uma alternativa possível para que se diminua o impacto ambiental causado pelo volume de lixo tecnológico depositado indevidamente em aterros. Tonani (2011) enfatiza que a reciclagem é o reaproveitamento de determinados materiais por meio de recurso que visa a recuperação de resíduos, para que ocorra a reutilização do bem, tanto para uso doméstico, como para uso na indústria, minimizando a quantidade de materiais que são descartados em aterros sanitários, acrescendo à vida útil destes e reduzindo os recursos ambientais extraídos pela ação do homem.

Os equipamentos eletroeletrônicos (EEE) são definidos como produtos que necessitam ser submetidos à utilização de corrente elétrica ou campo eletromagnético para o seu funcionamento. Quando chegam o limite de sua vida útil, esses produtos ou partes dos seus componentes são definidos 
como resíduos de equipamentos eletroeletrônicos (REEE). Os REEE são compostos por diversas substâncias, como plásticos, vidro e metais pesados, que provocam impactos à saúde humana e ao meio ambiente. Esses resíduos representam uma considerável parte de material ambiental tratado de forma indiferente por grande parte dos fabricantes no Brasil. Entretanto, representam uma oportunidade de mercado que requer competência e tecnologia para efetiva gestão ambiental (CARVALHO; XAVIER, 2014).

Destaca-se ainda, que alguns equipamentos eletrônicos são descartados por não terem mais serventia, outros são rejeitados em razão da obsolescência tecnológica, suas aplicabilidades se tornaram limitadas aos usuários. Em geral esses aparelhos são repassados para indivíduos, que não teriam condições de adquirir um produto, caracterizando essa ação como consumo em cascata (NATUME; SANT'ANNA, 2011).

A logística reversa na sua amplitude, compreende diversas operações relacionadas com a reutilização de produtos e materiais, além de recuperação sustentável de sucatas e subprodutos, no sentido de preservar o meio ambiente. Neste contexto, a logística reversa está ganhando cada vez mais espaço e importância nos cenários econômicos, legal, ambiental e de competitividade. É possível acompanhar esta visibilidade através dos investimentos na gestão do ciclo de vida de produtos e serviços, por meio dos avanços tecnológicos que possibilitam a entrada de novos produtos no mercado e consequentemente, a obsolescência de tais produtos, gerando um desordenado crescimento de resíduos em suas diversas formas (PEREIRA et al., 2012). Miguez (2012, p. 23), destaca ainda que "a indústria eletrônica é uma das que mais rapidamente crescem. Na concepção de Lacerda (2002) a logística reversa pode ser definida como sendo: 
Um processo de planejamento, implementação e controle do fluxo de matérias-primas, estoque em processo e produtos acabados (e seu fluxo de informação) do ponto de consumo até o ponto de origem, com o objetivo de recapturar valor ou realizar um descarte adequado (LACERDA, 2002, p. 34).

Carvalho e Xavier (2014) destacam que a gestão da cadeia reversa de resíduos tecnológicos possibilita reduzir a quantidade de materiais descartados indevidamente, que impactam a vida útil dos aterros, possuem valor agregado por meio da reciclagem, que podem ser resgatados através da logística reversa. Seu destino é definido de acordo com a sua condição, como: reuso, reciclagem, incineração, venda ao mercado secundário, ou destinadas aos aterros, que recebem também resíduos de limpeza urbana. (CARVALHO; XAVIER, 2014). Assim preocupação com a responsabilidade ambiental sobre os resíduos relacionados aos produtos, processos e serviços das empresas faz parte de agenda das organizações, com destaca Tachizawa e Faria (2007, p. 26) “a consciência ambiental e ecológica por parte das empresas resultou, também, na mitificação do conceito de qualidade do produto, que agora precisa ser ecologicamente viável".

Ainda se observa que a logística reversa, embora presente no meio organizacional, motivada pelo diferencial competitivo sustentável, obsolescência programada e busca pelo desenvolvimento sustentável, ainda não está presente entre os consumidores.

A PNRS, através da Lei $\mathrm{n}^{\mathrm{0}} 12.305$, de cinco de agosto de 2010, regulamentada pelo Decreto n⿳⺈ 7.404, de 23 de dezembro de 2010, institui um modelo participativo de implementação da responsabilidade compartilhada no sistema de logística reversa. Essa exigência constitucional é um marco histórico na gestão ambiental, pois estabelece rumos de gestão integrada, mobilização para gerenciamento ambientalmente adequado e 
inclusão social dos catadores (JARDIM; YOSHIDA; MACHADO FILHO, 2012). Conforme Brasil (2010) a obrigatoriedade da logística reversa estabelece que o fabricante, importador, distribuidor e comerciante sejam responsáveis pelo retorno dos produtos, após a utilização do consumidor, sem depender dos serviços de limpeza pública, promovendo a sua correta destinação dentro do contexto da logística reversa possibilitando recuperação dos produtos. Esta responsabilidade fica clara no Artigo 33, da citada Lei:

Art. 33. São obrigados a estruturar e implementar sistemas de logística reversa, mediante retorno dos produtos após o uso pelo consumidor, de forma independente do serviço público de limpeza urbana e de manejo dos resíduos sólidos, os fabricantes, importadores, distribuidores e comerciantes.

Jardim, Yoshida e Machado Filho (2012) apontam, que o segmento de eletrônicos se destaca nas ações de recebimento de materiais, através da logística reversa, com pontos de coleta disponibilizada pelos fabricantes em lojas que dispõe produtos á venda da mesma linha.

No entanto, a sofisticação e elevado custo nos processos de coleta e retorno dos resíduos ao processo inicial, podem acarretar dificuldades de tornar a logística reversa uma ferramenta de desenvolvimento econômico e social. De acordo com Jardim, Yoshida e Machado Filho (2012) ainda há discussões frente a incentivos econômicos visando reduzir os custos de esfera fiscal e tributária que dificulta a operacionalização da logística reversa de REEE.

A expansão da telefonia móvel no Brasil se deu através da acelerada evolução das tecnologias de telecomunicação, que no decorrer dos anos promoveu mais qualidade e velocidade na conexão para os usuários. O mercado de telefonia móvel continua a crescer rapidamente, mesmo com altos impostos 
incidindo sobre os serviços. Os telefones móveis já estão substituindo linhas fixas devido ao menor valor e maior praticidade, tornando-se principal meio de comunicação (TECHIN BRAZIL, 2016).

\section{METODOLOGIA}

Esta pesquisa, que teve como objetivo identificar os desafios e oportunidades da gestão da logística reversa de eletroeletrônicos para uma empresa operadora de celular, se caracterizou quanto aos seus objetivos como exploratória. A abordagem adotada foi através da combinação das metodologias qualitativa e quantitativa, que proporciona uma melhor compreensão dos problemas da pesquisa. Quanto aos procedimentos optou-se pelo estudo de caso, possibilitando detalhar os processos de logística reversa dos eletrônicos.

No que se refere a delimitação para apuração de dados, a pesquisa ocorreu em uma operadora de telefonia, com lojas localizadas na cidade de Porto Alegre, onde o sujeito foi o gestor responsável pela empresa na região sul do Brasil. Adicionalmente foi contatada a gestora que ocupou este cargo anteriormente, e agora representa outra organização do mesmo segmento, no sentido de dar uma maior abrangência aos dados, sobre sua opinião a respeito da logística reversa e sua gestão de uma forma geral sem mencionar a empresa pesquisada. A primeira pesquisada, doravante identificada como Gestora A, é responsável pela operação de logística reversa atualmente, ocupando o cargo de Analista de Sustentabilidade, com pós-graduação na área. A segunda, identificada com Gestora B, Engenheira Ambiental que ocupou o mesmo cargo até o ano de 2016. Após a concordância de ambas em participar da pesquisa, foi enviado o questionário através de e-mail, com roteiro semi-estruturado, com perguntas abertas, composto por 21 questões, atendendo o objetivo da pesquisa 
A pesquisa quantitativa abordou um grupo de 126 usuários de celular. Estes usuários selecionados através da lista de contatos da autora, nas redes sociais e pelo aplicativo de celular WhatsApp, utilizada uma metodologia semelhante a denominada como amostra snowball ou bola de neve. A pesquisa teve seu período de realização entre agosto e setembro de 2016, e mesmo buscando permissão da empresa e das gestoras pesquisadas, em tempo hábil, quanto ao término da pesquisa, não houve retorno quanto aos termos de consentimento, motivo pelo qual foi omitido o nome da empresa e das gestoras. O questionário autoaplicável, ficou disponível durante 35 dias no Google Docs. Foi propositalmente curto e simples, para não desestimular a participação dos pesquisados.

Optou-se pela realização da observação sistemática, ocorrendo a visita a seis lojas da operadora. Durante as visitas a pesquisadora não se identificou como tal, e seguiu um roteiro de observações. A etapa de campo foi precedida de pesquisa documental, possibilitando o conhecimento sobre o programa de logística reversa desenvolvido pela empresa pesquisada. Os documentos pesquisados foram folders distribuídos nas lojas da operadora e material informativo disponível no site da operadora.

Uma vez coletados, os dados foram organizados e se procedeu, quando possível, as comparações entre os dados obtidos com a pesquisa qualitativa e quantitativa com a observação e de dados provenientes da pesquisa documental, que foram de grande importância, já que supriram lacunas da coleta qualitativa. Uma vez confrontados os dados o próximo passo foi a análise interpretativa dos mesmos, técnica definida por Marconi e Lakatos (2010) como aquela que busca "fazer uma crítica, do ponto de vista da coerência interna e validade dos argumentos empregados no texto e da profundidade e originalidade dada à análise do problema, realizar uma apreciação 
pessoal e mesmo emissão de juízo sobre as ideias expostas e defendidas." (MARCONI; LAKATOS, 2010, p. 32).

\section{RESULTADOS}

A empresa objeto deste estudo de caso, possuiu uma visão abrangente dos negócios e do propósito de ter o cliente no centro de tudo o que a empresa faz, respondendo às suas necessidades num contexto de mundo cada vez mais convergente e globalizado. Mostra um portfólio amplo e completo, abrangendo atualmente serviços de banda larga fixa e móvel, voz, ultra banda larga, televisão (TV) paga e tecnologia da informação (TI), se posicionando favoravelmente para satisfazer as necessidades de seus clientes e atingir crescimento em novas receitas.

Para identificar como ocorre a gestão dos resíduos eletroeletrônicos na organização pesquisada, foram elaboradas dez perguntas destinadas a Gestora A, Analista de Sustentabilidade da operadora pesquisada, que foi inicialmente questionada sobre o desenvolvimento de algum programa de logística dentro da organização. A Gestora A esclareceu que um dos principais riscos ambientais da área de telecomunicações está associado à destinação de resíduos eletrônicos. O processo de logística reversa se dá em duas frentes: a retirada de equipamentos pela organização nos pontos de uso (pontos comerciais, residências, prédios entre outros) e a entrega de celulares e acessórios em todas as lojas e revendas, através de eco-pontos de recolhimento de resíduos. Esta ação é abordada por Carvalho e Xavier (2014) onde afirmam que a gestão da LR de resíduos tecnológicos reduz o volume de materiais eliminados de forma inadequada, permitindo o reaproveitamento dos materiais, possibilitando que tenham seu destino definido conforme sua condição.

Na sequência a Gestora A relatou de que forma ocorre a coleta dos REEE, e a divisão da utilização do material re- 
aproveitado, foi detalhado conforme os serviços oferecidos pela mesma, como a TV paga e banda larga, sendo mais de 30 mil pontos com equipamentos, em algumas situações existem locais com dois ou mais equipamentos instalados. De acordo com Gestora A:

\begin{abstract}
Esse volume demanda um grande esforço de logística reversa, que é empregado não só para recolher os equipamentos que precisam ser substituídos, mas para reaproveitá-los quando ainda apresentam condições técnicas de uso. Nesse caso, é feita triagem, selecionando os que podem, potencialmente, ser reaproveitados em outras instalações. Os aptos são enviados para a manutenção, que avalia e faz uma nova triagem, selecionando equipamentos que podem retornar à operação. Os considerados não aptos vão para destinação adequada de lixo eletrônico. (GESTORA A, 2016).
\end{abstract}

A Gestora A complementou a informação, acrescentando que os celulares, baterias, modens e acessórios fazem parte do programa de incentivo a reciclagem, que consiste em descartar os equipamentos em desuso para serem reciclados e destinados de forma ambientalmente adequada através de empresas parceiras da operadora, especialistas em logística reversa global e reciclagem de materiais eletrônicos. Destacando ainda, que a operadora é pioneira em programa de logística reversa pós-consumo, com um programa o piloto lançado em 2006 e implantado em todo o Brasil em 2008. A pesquisa documental revelou que o programa de logística reversa da operadora é amplamente divulgado no site da operadora.

A Gestora A acrescentou que no processo de triagem e distribuição são classificados os resíduos conforme sua possibilidade de reuso, os aparelhos celulares apresentam diversos componentes como ouro, prata e cobre que podem ser reutilizados como matéria-prima para diversos fins. A gestão dos resíduos adotados pela operadora está alinhada à definição de Suslick, Machado e Ferreira (2005), que apontam a maneira 
mais lógica de alcançar o desenvolvimento sustentável, através dos 4Rs, em que são necessários reduzir, reutilizar, reciclar e recuperar o bem evitando a geração de resíduos, para que se alcancem benefícios ambientais, sociais e econômicos. Estes três pontos, de acordo com Xavier e Correa (2013) formam a base da sustentabilidade.

Quanto a recuperação dos resíduos, a Gestora A afirmou que, entre 2006 e 2014, a operadora atingiu a marca de um milhão de aparelhos telefônicos entre os 3,4 milhões de itens coletados, exemplificando o caso específico do Estado do Pará, onde em 2014 foram contabilizados 810 itens e 241 celulares. Em 2015, este total chegou a 294 itens coletados com cerca de 100 aparelhos celulares até setembro. A pesquisa documental, no Relatório de Sustentabilidade 2015 disponível no site da empresa, corroborou o exposto pela Gestora A, indicando o percentual de resíduos reciclados foi de $97,8 \%$, frente a $2,2 \%$ de resíduos dispostos em aterro. O Relatório de Sustentabilidade 2015 ainda aponta que a meta para recuperação de equipamentos é de 1,6 milhão de aparelhos.

Em consonância com o exposto pela Gestora A e com o divulgado no Relatório de Sustentabilidade 2015 da operadora pesquisada, a ONU (2015) reforça que, mesmo havendo informações sobre o impacto negativo, a existência de uma legislação específica, a PNRS, que condiciona a responsabilidade compartilhada a todos os envolvidos no contexto logístico pelo descarte apropriado e as organizações tomando a frente para que o lixo eletrônico seja diminuído e impedido de entrar em contato com a natureza. Dados da ONU (2015) demonstram um desenfreado crescimento de lixo eletrônico, onde foi aferido que houve um acúmulo de mais de 1,4 milhão de toneladas de REEE produzidas no país.

A Gestora A foi questionada sobre o destino dos REEE coletados no programa de logística reversa pós-consumo e 
sobre o processo de reutilização e reciclagem, ao que a pesquisada esclareceu que:

Os aparelhos coletados passam por triagem e são destinados corretamente para reciclagem, com empresas parceiras da operadora, especialistas em logística reversa global e reciclagem de materiais eletrônicos. Esse processo é importante, pois os aparelhos celulares são compostos por diversos componentes - como ouro, prata e cobre -, que podem ser reutilizados como matéria-prima para diversos fins. Após essa etapa, o material é enviado para a reciclagem. (GESTORA A, 2016).

Como se pode observar, neste ponto as respostas da Gestora A foram sucintas, motivando a pesquisa documental. Chiaradia (2012) revelou que todo o material recolhido é processado e os procedimentos de logística, desmanofatura e reciclagem ficam a cargo de uma empresa terceirizada, a Belmont Trading, que detém esta tecnologia e licença ambiental para tratar destes processos. Os aparelhos em bom estado, que podem ser reutilizados, passam por uma limpeza de memória e são dirigidos para outros mercados, alguns países sul americanos e africanos. Os que não têm condições de uso são enviados a empresas de reciclagem. As peças eletrônicas são enviadas para serem recicladas na Sipi Metais nos Estados Unidos; as partes plásticas, tem como destino a empresa Belmonte Trading, no México; e as baterias seguem para a empresa norte-americana Inmetco. (CHIARADIA, 2012)

Quanto ao posicionamento da organização pesquisada referente a motivação nas práticas de logística reversa, a Gestora A declarou que a empresa é instigada pelo compromisso com a postura responsável na gestão de resíduos sólidos. Alguns autores, referência no assunto, entre eles Alencastro (2012) e Carvalho e Xavier (2014), apontam uma propagação do interesse das empresas em adotar práticas sustentáveis em seu plano de ação, mesmo que estas ações sejam através da 
legislação vigente, como a PNRS, que apresenta orientações sobre o gerenciamento de resíduos sólidos e define as responsabilidades de cada setor envolvido, incluindo os resíduos dos equipamentos eletroeletrônicos no âmbito da logística reversa. Por sua vez, Zambon e Ricco (2009) apontam que esse modelo de gestão vem sendo fomentado pelo novo contexto mundial, onde as empresas tornam-se ambiental e socialmente responsáveis. Através dessa postura, é presumível o crescimento econômico da organização, sendo também uma forma de contribuir com a longevidade do negócio, assim sendo uma prática possível a todos.

Visando verificar as vantagens ambientais e econômicas da logística reversa dos resíduos eletroeletrônicos para a operadora de celular, foram realizadas onze perguntas a Gestora A. Assim ao ser questionada sobre as vantagens ambientais e econômicas provenientes da logística reversa para a organização, a Gestora A entende que a vantagem é a possibilidade da reciclagem dos produtos, pois através disso é possível reaproveitar materiais que até então seriam inúteis, reduzindo assim o passivo ambiental que é produzido, e algumas vezes ignorado, como fonte de renda. Afirmando neste contexto, que o retorno financeiro alcançado com o programa de logística reversa de REEE é baixo, sem a obtenção de incentivos fiscais e nem parcerias com instituições, não sendo possível identificar vantagem competitiva perante a concorrência através de destas ações. Como declarou a Gestora A ao ser questionada sobre o tempo e o valor de retorno do investimento "Este investimento não tem retorno, pois a receita gerada é muito baixa." (GESTORA A).

Apesar da perspectiva apresentada pela Gestora A, Pereira et al. (2012) salientam que a LR vem ganhando mais notoriedade e importância nos cenários econômico, legal, ambiental e de competitividade, esta visibilidade é possível 
através dos investimentos direcionados a gestão do ciclo de vida dos produtos.

Entre os anos de 2006 a 2012 a operadora não teve custos com o programa, pois todo ele foi pago pelos resultados advindos das empresas parceiras com a reciclagem das partes plásticas e metálicas. Assim se observa que, em consonância com a literatura, a operadora atende ao que prevê a PNRS, denominada de responsabilidade compartilhada. Por esta premissa fabricantes, importadores, distribuidores e comerciantes, que colocam produtos no mercado, têm responsabilidade solidária pela sua recuperação, após o descarte pelo consumidor, promovendo a sua correta destinação, dentro de um contexto de logística reversa, como prevê o Artigo 33 da Lei no 12.305 (BRASIL, 2010). Sob esta ótica, a operadora fica resguardada de multas ou processos por descumprir a legislação, sendo esta uma vantagem econômica. De forma concorrente, se destaca a opinião de Aligleri, Aligleri e Kruglianskas (2009), quando os autores ressaltam que a implantação de uma política de recolhimento de produtos usados e descartados precisa estar inserida nas ações das organizações varejistas, pois a logística reversa abre novas oportunidades de mercado baseadas na reciclagem, no descarte e na responsabilidade social, sendo esta uma vantagem competitiva.

Para ampliar os resultados obtidos, se buscou a visão da Gestora B, profissional da área de Engenharia Ambiental que em de sua trajetória profissional teve a oportunidade de conhecer e compartilhar o processo de logística reversa da organização pesquisada. Percebeu-se que há consonância entre as pesquisadas, pois a Gestora B afirmou que as reais vantagens alcançadas pela logística reversa são a possibilidade de evitar a proliferação de descarte em aterros, que geram custos e eventualmente contaminação do ambiente; alinhar a empresa à legislação vigente, que estabelece a responsabilidade 
compartilhada; além de intensificar a competitividade e estratégia das organizações. Neste ponto a Gestora B acredita que a sociedade está sempre em busca de empresas sustentáveis e ambientalmente responsáveis, que tragam benefícios à sociedade, devido à retirada dos insumos em desuso, possibilitando um destino correto e sua possível reutilização.

Quanto aos recursos captados através da logística reversa nas empresas, a Gestora B, afirma que em geral são poucos, destinados às áreas de sustentabilidade, marketing e a própria logística. Sobre os incentivos recebidos pelas empresas, a Gestora $B$ relatou que variam de acordo com o ramo de atividade, assim como as parcerias para coleta de materiais em seus estabelecimentos. Apesar de ambas as pesquisadas não enfatizarem os ganhos resultantes dos programas de logística reversa na organização pesquisadas e em outras do mesmo ramo, tanto a existência destes programas em várias operadoras de celular, instituições financeiras e até mesmo supermercados, como a literatura, indicam o oposto. Neste sentido Dullius (2015) ressalta que, com a implantação de sistema de gestão ambiental, é possível trazer resultados vantajosos às organizações, entretanto, salienta que apenas a operação e estabelecimento de um sistema de gestão não resultarão em melhorias imediatas. A sustentabilidade nas organizações não é mais um diferencial no mercado, é um pré-requisito para sobrevivência, pois como afirma Tachizawa e Faria (2007), a qualidade também já foi considerada um custo e a indústria resistiu às mudanças, mas com o tempo passou a fabricar produtos de qualidade inquestionável e defeitos nulos. No mercado contemporâneo, a qualidade perfeita é uma inquestionável ferramenta competitiva, assim como a sustentabilidade esta sendo considerada, nos dias de hoje, como pré-requisito para que uma empresa entre no mercado.

No que se refere a atitude de um grupo de usuários de celular com relação ao descarte dos aparelhos usados, foram 
elaboradas sete perguntas, posteriormente divulgadas através das ferramentas Survey e Google Docs, propagadas através do aplicativo WhatsApp, redes sociais e e-mail corporativo, onde foi solicitado aos componentes das listas de contatos que divulgassem as perguntas a uma ou mais pessoas de seus contatos. Os dados foram coletados através de 126 respondentes que manifestaram seu conhecimento frente ao tema apresentado. Destas, foram definidas duas perguntas de identificação do perfil do usuário de telefone celular. Com relação ao gênero e faixa etária, houve a predominância de respondentes do gênero feminino, na faixa etária entre 31 e 40 anos. Quanto a idade, os demais pesquisados, resultam $37 \%$ dos resultados, somam entre 21 e 30 anos de idade; $17 \%$ com idade entre 41 e 50 anos; e a minoria, com mais de 51 anos, e menos de 20 anos; correspondem a $4 \%$ e $2 \%$, respectivamente.

Uma vez definido o perfil geral dos usuários, as próximas cinco perguntas discorreram sobre o assunto estudado, abordaram quatro pontos: o tempo de troca de aparelho celular; o que motivou a troca; o destino dos aparelhos inutilizados; e o conhecimento dos usuários sobre a existência de programa logística reversa em sua operadora. Sobre o tempo no qual cada usuário realizou a última troca de aparelho, sendo as respostas expostas no Gráfico 1 .

Com relação a este assunto, a bibliografia mostra um quadro preocupante, afirmando que a maior parte dos consumidores efetua a troca de aparelho com três anos de uso (MIGUEZ, 2012), com apenas um ano de uso e até mesmo ao primeiro problema técnico (IDCE, 2014), indicando uma velocidade crescente na troca dos aparelhos ao longo do tempo, entre os anos de 2012 e 2014. Conforme exposto no Gráfico 1, se observa que $12 \%$ dos pesquisados efetuou a troca do aparelho celular há três anos ou mais; a maioria dos pesquisados, correspondendo $32 \%$, efetivou a troca há dois anos; e $25 \%$ dos 
pesquisados substituíram seus aparelhos há um ano; e um último grupo de pesquisados, perfazendo $31 \%$ dos pesquisados realizou a troca com menos de uma ano de uso. A pesquisa não corroborou os dados de Miguez (2012), cuja maioria dos pesquisados realizou a troca com três anos de uso.

Gráfico 1 - Tempo de troca de celular

\section{Tempo de troca do celular}

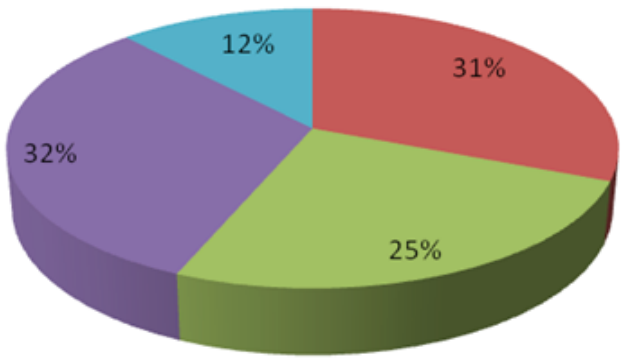

- Durante este ano

- Há 1 ano

- Há 2 anos

- Há 3 anos ou mais

Fonte: autora, 2016

Estas trocas justificaram-se pelo limite de vida útil dos aparelhos, que são no máximo três anos de uso. No Brasil existe um elevado número de substituição de aparelhos por obsolescência programada, baseado no período do ciclo de vida, e motivada pelo avanço tecnológico oferecido pelos fabricantes. Este crescimento é abordado por Miguez (2012) quando refere o crescimento da indústria eletrônica acompanhada da elevada obsolescência dos produtos e descarte. Também foi investigada motivação para troca de aparelho, sendo os resultados expostos no Gráfico 2, onde se observa que $58 \%$ dos pesquisados apontaram a necessidade; $40 \%$ os avanços tecnológicos; $2 \%$ realizaou a troca por apelo comercial; e nenhum dos pesquisados apontou o incentivo dado pelas 
operadoras, como de programas de descontos, pontuações, fidelidade entre outros, como motivador para troca.

Uma parcela siginificativa de $58 \%$ dos pesquisados apontam a necessidade como fator de troca, manifestaram-se espontaneamente indicando a perda ou roubo do aparelho como motivador da troca, atestando a atual conjuntura relacionada a segurança pública na cidade de Porto Alegre. O segundo fator que motivou os pesquisados na troca do celular, somando $40 \%$ dos respondentes, foi o avanço da tecnologia. Carvalho e Xavier (2014) corroboram esta observação, afirmando que o Brasil é o país onde há mais substituição de aparelhos por obsolescência programada. Os autores reiteram que o avanço tecnológico propiciou crescimento e melhoria de vida das pessoas, podendo ser observada no contínuo desenvolvimento dos aparelhos. Apenas $2 \%$ dos pesquisados relatam a troca motivada pelo apelo comercial, quando são atraídos pelas propagandas e datas comemorativas. Os demais pesquisados enfatizam autonomia da troca de seus aparelhos, onde ninguém foi incentivado pela operadora para efetuar a troca ou estimulados por meios de programas de descontos, pontuações, fidelidade entre outros.

É interessante observar que, sempre que foi necessário, ocorreu a troca. Nenhum dos pesquisados, inclusive entre os ficaram sem aparelho devido ao furto ou roubo, se observou a manifestação de ficar sem aparelho algum. Esta é uma realidade corroborada pela ANATEL (2015), que aponta a grande importância dos celulares no cotidiano dos indivíduos, que estão cada vez mais conectadas, devido a necessidades profissionais e pela rotina, de estar virtualmente em contato com outras pessoas. Os smartphones substituem vários eletroeltrônicos, como máquina fotográfica, relógio, despertador e muitas vezes até mesmo o computador pessoal, sendo utilizado para receber e enviar mails e outros documentos. Natume e 
Gráfico 2 - Motivo da troca do aparelho

\section{O que motivou a troca?}

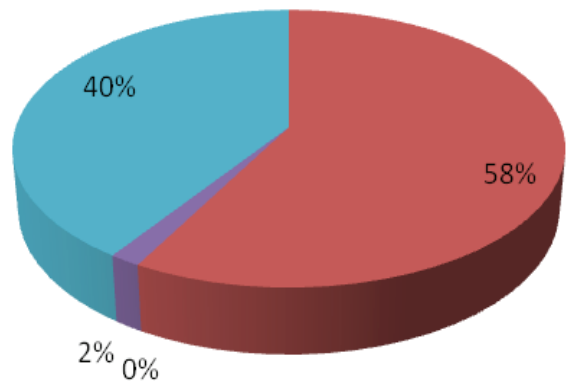

necessidade

- Incentivo da operadora

Apelo comercial

- Avanço tecnológico

Fonte: autora, 2016

Santanna (2011) fazem referência ao destino dos aparelhos inutilizados, ressaltando que alguns equipamentos são descartados pela sua inutilidade, em razão da obsolescência tecnológica, ou quando suas aplicabilidades ficam limitadas. Em algumas situações são passados a outros indivíduos, que não teriam condições de adquirir o produto, caracterizando essa ação como consumo em cascata, como podem ser observados os dados apresentados no Gráfico 3.

Diante disto, a maioria dos respondentes, representados por $48 \%$ do total, fazem doação dos aparelhos, destinando-os geralmente a familiares, que os utilizam com funçoes básicas, sem muitos processos tecnológicos, realizando e recebendo ligações, prolongando a vida útil destes aparelhos (GRÁFICO 3). As trocas ou vendas são representadas por $29 \%$ dos respondentes, estas trocas geram descontos nas compras nas operadoras. 
Gráfico 3 - Destino dos aparelhos inutilizados

\title{
Destino dos aparelhos que não são mais
} utilizados

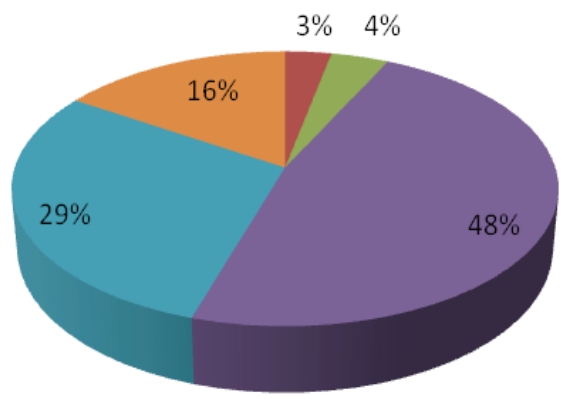

\author{
- Descarta na operadora \\ - Joga no lixo seco \\ - Faz doação do aparelho \\ - Troca ou vende \\ nuarda em casa
}

Fonte: autora, 2016

Sobre o tema ainda é importante ressaltar que a operadora pesquisada mantém um programa de descontos na troca do parelho celular, este programa é mais uma evidência da importância que a logísitica reversa representa para a operadora em questão, embora as gestoras entrevistadas tenham enfatizado que não há ganhos significativos com o programa, pois a receita resultante de destes programas é muito baixa (GESTOR A; GESTORA B, 2016) e não é possivel identificar vantagem competitiva perante a concorrência (GESTORA A, 2016).

Ainda discorrendo sobre os resultados alcançados no Gráfico 3, se observa que $16 \%$ dos pesquisados declarou que mantém os aparelhos celulares fora de uso guardados em casa. Segundo os pesquisados, o motivo de guardar o paparelho é a possibilidade de, em algum momento, os mesmos poderem ser reutilizados. Entretanto a bibliografia mostar uma outra realidade, em pesquisa com pergunta semelhante, Rozzett, Alfinito e Assumpção (2013), afirmam que uma parcela dos consumidores mantém este hábito por não saber o que fazer com os aparelhos.

130 ReMAS • Revista Metodista de Administração do Sul, v. 2, N. 1, 2017 
Uma parcela de $4 \%$ dos pesquisados afirmou que jogam o aparelho usado no lixo seco, entretanto um mau encaminhamento destes resíduos, fato que não é incomum na realidade urbana da cidade, onde a ação dos catadores desorganizados muitas vezes antecede a coleta formal da prefeitura, pode ser o início do processo de contaminação do meio ambiente, devido a elevada quantidade de metais na composição dos resíduos dos aparelhos eletroeletrônicos (NATUME; SANT'ANNA, 2011), que possuem características tóxicas, apresentando significativo risco à saude humana e a qualidade ambiental (PNRS). A impossibilidade de aproveitamento faz com que recursos sejam retirados da natureza para produção de novos aparelhos.

O Gráfico 3 ainda mostra que 3\% dos pesquisados descarta o aparelho celular usado na operadora, para que tenha o destino adequado. Neste sentido se destaca Tonani (2011), que frisa a importância da recuperação dos resíduos para que se torne possível a reutilização dos mesmos, minimizando a quantidade de insumos descartados de forma incorreta em locais inapropriados, contribuindo para o crescimento da vida útil e evitando a extração de novos bens da natureza.

As últimas duas questões propostas buscaram verificar o conhecimento dos consumidores sobre o serviço de descarte oferecido pelas lojas e operadoras que comercializam aparelhos celulares e o conhecimento destes sobre a reciclagem dos aparelhos. O resultado que focou no conhecimento dos serviços de descarte oferecido pelas operadoras está expresso no Gráfico 4. 
Gráfico 4 - Conhecimento sobre o serviço de descarte na loja

\section{Tem conhecimento se a sua operadora oferece $o$ serviço de descarte de aparelhos na loja?}

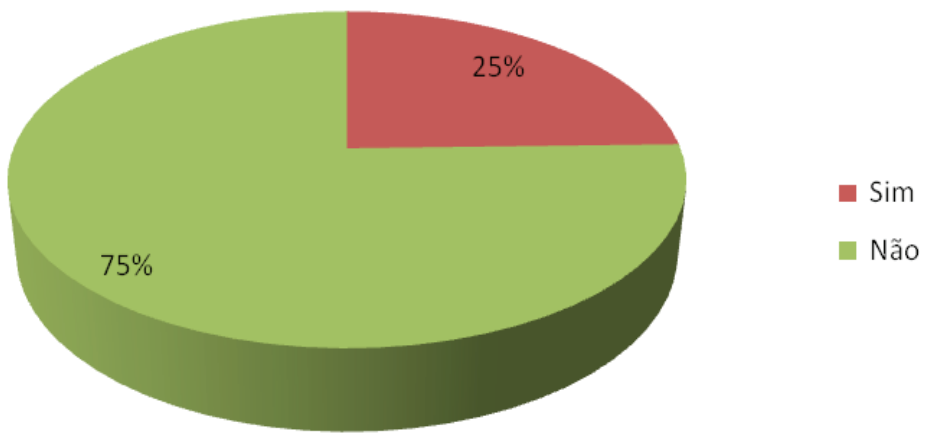

Fonte: autora, 2016

No Gráfico 4 se pode observar que $75 \%$ dos pesquisados não possuem conhecimento sobre este serviço; enquanto que $25 \%$ sabem sobre o descarte oferecido pelas lojas e operadoras de celulares. Neste ponto Leite (2009) ressalta que é necessário que as empresas instrumentalizem o fluxo físico do descarte da sociedade em geral, permitindo que estes resíduos retornem ao ciclo produtivo. Esse processo torna possível a reutilização quando não é mais utilizado para fim o proposto, agregando valor ao processo logístico e ao bem, integrado novamente ao ciclo de produção. Entretanto a pesquisa indicou falta informação ao usuário do celular.

Frente a este fato se buscou na pesquisa documental verificar se a operadora objeto deste estudo divulga suas ações de logística reversa ou se informa sobre a sustentabilidade a seus clientes. Constatou-se que a empresa mantém em seu site material interativo e interessante sobre o impacto dos eletroeletrônicos sobre o meio ambiente, tanto sobre a sua fabricação, 
como uso e descarte responsável. O programa é bastante amplo e abrange informações desde a extração da matéria prima para fabricação dos aparelhos, durabilidade das baterias, responsabilidade compartilhada da cadeia (fabricante, operadora, consumidor) e o destino final dos aparelhos, de uma forma interativa e agradável. A linguagem utilizada é acessível e site é visualmente bonito e intuitivo, tornando agradável a navegação, de forma paradoxal conclui coma frase: “Chegou a hora de trocar de celular? Não esqueça: nada de deixá-lo no fundo da gaveta! Busque pontos de descarte e reciclagem dos aparelhos, contribuindo com o meio ambiente" (OPERADORA PESQUISADA, 2016). Esta ação encontra apoio na bibliografia, pois Xavier e Correa (2013) afirmam que as medidas tomadas pelas empresas, que adotam a gestão ambiental orientada pela sustentabilidade, alcançam uma vantagem competitiva perante seus concorrentes, esta estratégia utilizada pelas organizações tem como objetivo a redução dos impactos econômicos, sociais e ambientais.

A última questão dirigida aos usuários abordou o conhecimento que cada um tem sobre a reciclagem em suas respectivas operadoras, conforme expresso no Gráfico 5, onde se observa que $88 \%$ dos pesquisados não têm conhecimento sobre o que é feito com os aparelhos que são descartados; e 12\% sabe o que é feito após o descarte adequado realizado em pontos de coleta.

A operadora em questão oferece aos consumidores dispensers para descarte dos aparelhos e acessórios, na forma de urnas personalizadas, produzidas com papel reciclável e urnas acrílicas, disponíveis nas lojas em geral em local visível ao público. Carvalho e Xavier (2014) ressaltam a importância desta alternativa, que reduz o impacto ambiental causado pelo volume de lixo tecnológico depositado de forma incorreta em locais e com elevado risco de contaminação ambiental. 
Gráfico 5 - Conhecimento sobre a destinação dos aparelhos descartados

\section{Tem conhecimento se a sua operadora faz a reciclagem de aparelhos inutilizados?}

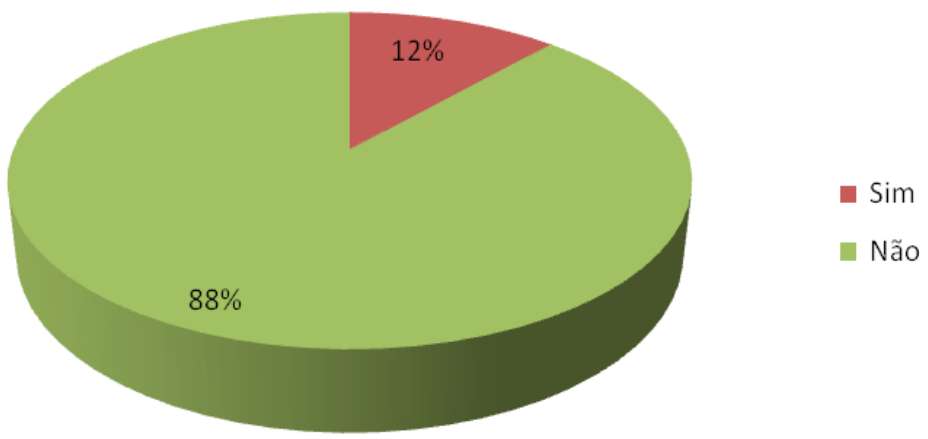

Fonte: autora, 2016

Como parte da pesquisa foi realizada a observação sistemática em seis lojas da operadora, com o intuito de verificar o conhecimento dos colaboradores quanto ao serviço oferecido e a disponibilidades das urnas de descarte. Em conversa informal com colaboradores, em cada uma das lojas se constatou que os colaboradores da organização não possuem conhecimento específico dos processos que envolvem a logística reversa dos aparelhos que são depositados nos locais, desconhecendo desde o destino dos aparelhos e até mesmo o que são feito destes após o descarte, assim como a importância da realização da coleta.

No momento do descarte não há qualquer tipo de burocracia, o material é depositado em urnas em locais estratégicos nas lojas (FIGURA 1). Entretanto não há material disponível para a divulgação do serviço oferecido pela operadora, nem cartaz ou aviso para atrair a atenção dos clientes. 
DESAFIOS E OPORTUNIDADES DA LOGÍSTICA REVERSA

DE ELETROELETRÔNICOS EM UMA OPERADORA DE

CELULAR NA VISÃO DE GESTORES E USUÁRIOS

Figura 1 - Urnas de descarte de três lojas da operadora pesquisada
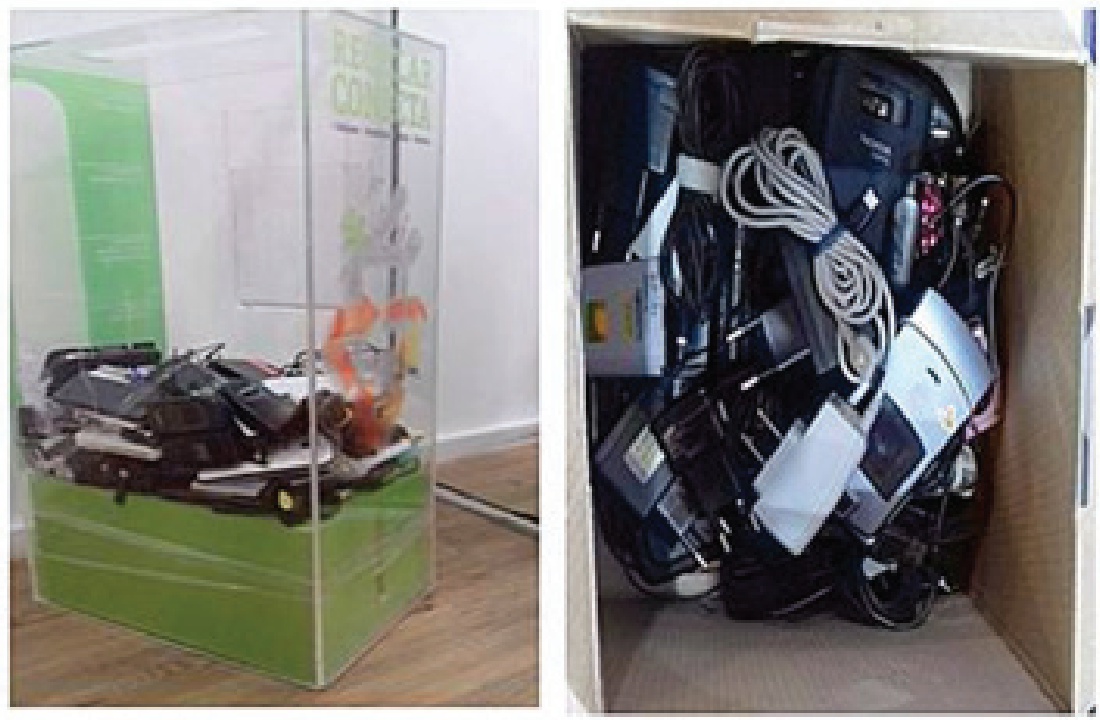

Fonte: autora, 2016

Apesar da falta de divulgação e de conhecimento sobre a coleta dos aparelhos celulares pelos usuários, como apresentado nesta pesquisa, foi possível verificar nas lojas visitadas que haviam materiais descartados, conforme a Figura 1. De forma a complementar as informações, já que os pesquisados não identificaram a operadora, a pesquisadora percorreu outras quatro lojas de operadoras diferentes para observar se todas oferecem o mesmo serviço, confirmando que todas realizam a coleta de celulares e acessórios. Em uma das operadoras foi exigido para o descarte o preenchimento de um termo de descarte de aparelho celulares baterias e acessórios de celulares. O preenchimento deste documento poderia inibir ou dificultar o descarte, entretanto não foi isso que se observou, já que a urna de descarte desta operadora estava cheia como as demais. 


\section{CONSIDERAÇÕES FINAIS}

Quanto a gestão dos resíduos eletroeletrônicos na organização pesquisada, se observou que a operadora possui pontos de coleta de REEE e também um programa de reciclagem que incentiva o descarte dos equipamentos para serem reciclados e destinados de forma ambientalmente adequada. O programa tem abrangência nacional, no qual a empresa faz um amplo trabalho publicitário em seu site e recolhimento em urnas específicas para este fim em suas lojas, podendo ser descartados os celulares, baterias e acessórios obsoletos dos clientes ou não clientes, sendo oferecidos inclusive descontos para os clientes que realizarem a troca de aparelho. Os materiais recolhidos são triados e encaminhados para seus destinos. Os aparelhos e componentes que ainda possuem condições de uso são encaminhados a manutenção, aqueles sem condições de uso são enviado à reciclagem onde há a separação dos componentes de cada aparelho, os que possuem metais são encaminhados a empresa terceirizada no exterior, que realiza o processo que possibilita a reutilização desse bem em outros fins produtivos. Essas ações são impulsionadas pelo compromisso com a postura responsável na gestão de resíduos sólidos que reduz o material descartado no meio ambiente.

No que refere as vantagens ambientais e econômicas da logística reversa dos resíduos eletroeletrônicos para a operadora de celular, foi observado que a principal vantagem de toda operação é a ambiental, esse processo evita que o material tenha descarte final incorreto, e por consequência traga contaminação ao meio ambiente, somado a possibilidade do reuso de matérias primas não renováveis. De acordo com as gestoras pesquisadas o retorno financeiro não é expressivo e a verba resultante é destinada a uma fundação a qual a operadora é mantenedora. $\mathrm{O}$ alinhamento da empresa com o que prevê a PNRS, que é a responsabilidade compartilhada e a 
obrigatoriedade com a logística reversa de REEE também foi identificada como uma vantagem econômica, uma vez que previne multas e processos.

Aferido sobre a atitude de um grupo de usuários de celular com relação ao descarte consciente de aparelhos telefônicos usados, percebeu- se que a troca dos aparelhos baseados no tempo de vida útil é de no máximo três anos, impulsionadas pelo avanço tecnológico e suas limitações de uso, existindo um elevado número de substituição de aparelhos por obsolescência programada. Sempre que necessário ocorreu a troca, ressaltando a grande importância dos celulares do dia a dia dos indivíduos, seja ela por questões profissionais ou necessidade de manter-se conectado. Quando os aparelhos tornam-se sem utilidade àqueles usuários, a maioria das pessoas que colaboraram com a pesquisa, destinam esses aparelhos a doações, geralmente a familiares que não possuem exigência tecnológica. Dentro deste item, foi exposto a falta de conhecimentos dos usuários sobre a logística reversa dos aparelhos, onde a maioria desconhece a importância do descarte adequado e o que ocorre após o descarte.

Através desta pesquisa, pode-se observar que faltam incentivos para que a logística reversa possa se expandir, e os resultados obtidos com este tipo de ação ainda estão limitados pela falta de adesão dos usuários a esta prática. A competitividade estabelecida entre as organizações pode influenciar as organizações a manterem as ações de logística reversa, pois mesmo não havendo retorno financeiro expressivo, as vantagens ambientais obtidas acarretam na diminuição de lixo eletrônico descartado de forma incorreta.

Entretanto a pesquisa de campo mostrou que predomina o desconhecimento dos envolvidos no processo, desde gestores, funcionários das lojas e usuários da operadora, sobre o programa de coleta e reciclagem. É possível até mesmo afirmar 
que há falta de engajamento da sociedade com o todo, fazendo com que o processo de logística reversa dos REEE, seja pouco efetivo frente ao que se poderia esperar.

Sendo assim, se pode apontar como maior desfio à gestão da logística reversa em uma operadora de celular a sensibilização, seguida de informação e da educação dos envolvidos, pois sem a participação de todos os interessados estes programas não alcançarão a sua plenitude. Embora a PNRS oportunize o avanço no comportamento ambiental, e as empresas queiram dar continuidade a logística reversa, fica claro a falta incentivos fiscais, impossibilitando que o processo se torne menos oneroso.

Quanto as oportunidades, se destaca que, frente ao exposto ainda há muito espaço para o crescimento da logística reversa, que apesar de uma ação necessária à sustentabilidade em longo prazo, também representa recursos que podem reverter à empresa na forma de ganhos financeiros e na perenização dos negócios, já que os metais, elementos fundamentais na fabricação dos aparelhos eletroeletrônicos, embora recicláveis, são não-renováveis e, em algum momento, poderão deixar de existir em quantidade suficiente para atender as demandas da sociedade, cada vez mais ávida pela tecnologia e pelas novidades. Além disto as ações de logística reversa, tornaram-se frequentes nas empresarial, influenciando na competitividade e no sucesso dos negócios. Essa prática permite que as organizações busquem possibilidades de fortalecimento e obtenção de vantagem competitiva, tendo em vista que, para disponibilizar um sistema de logística reversa, é necessário dispor de recursos que possam sustentar esse processo e que esse planejamento venha a dar retorno

\section{REFERÊNCIAS}

AGÊNCIA NACIONAL DE TELECOMUNICAÇÕES-ANATEL. Brasília. Disponível em: <http://www.anatel.gov.br/institucional/ 
index.php?option $=$ com_content\&view $=$ article\&id=717>. Acesso em: 30 mar. 2015.

ALENCASTRO, M. S. C. Empresas, ambiente e sociedade: introdução à gestão socioambiental corporativa. Curitiba: Intersaberes, 2012.

ALIGLERI, L.; ALIGLERI, L. A.; KRUGLIANSKA, I. Gestão socioambiental: responsabilidade e sustentabilidade do negócio. São Paulo: Atlas, 2009.

BRASIL. Lei no 12.305, de 2 de agosto de 2010.Institui a Política Nacional de Resíduos Sólidos; altera a Lei no 9.605, de 12 de fevereiro de 1998; e dá outras providências. Disponível em: <http:// www.planalto.gov.br>. Acesso em: 20 set. 2015.

CARVALHO, T. C. M.; XAVIER, L. H. Gestão de Resíduos: eletroeletrônicos uma abordagem prática para a sustentabilidade. Rio de Janeiro: Elsevier, 2014.

CHIARADIA, I. Gestão de resíduos eletrônicos em uma operadora de telefonia celular. Trabalho de conclusão do curso de Administração do Centro Universitário Metodista - IPA. Porto Alegre, 2012, 73 p.

DULLIUS, T. L. Análise da logística reversa de resíduos eletroeletrônicos em assistências técnicas na cidade de Lajedo-RS. TCC (Bacharel em Engenharia Ambiental) UNIVATES Disponível em https://www.univates.br/bdu/bitstream/10737/949/1/2015TiagoLuis Dullius.pdf Acesso em: 14 maio. 2016.

EGLER, T. T. C. Redes tecnossociais e democratização das políticas públicas. Sociologias, Porto Alegre, n. 23, p. 208-236, Abr. 2010 Disponível em: <http://www.scielo.br/scielo.php?script=sci_arttext\&pid=S1517-45222010000100008\&lng=en\&nrm=iso $>$. Acesso em: 12 jun. 2016.

INSTITUTO BRASILEIRO DE DEFESA DO CONSUMIDOR-IDEC.O DESTINO dos aparelhos usados. Revista do IDEC, n.184,p.20-22, 2014... Disponível em:<http://www.idec.org.br/em-acao/revista/faltafruta-na-caixinha/materia/o-destino-dos-aparelhos-usados $>$. Acesso em: 08 maio. 2016.

INSTITUTO BRASILEIRO DE GEOGRAFICA E ESTATÍSTICA - IBGE. Censo demográfico 2010. Rio de Janeiro, Brasília, 2010. Disponível em:<http://www.ibge.gov.br/home/estatistica/populacao/censo2010/ default.shtm>. Acesso em: 02 mar.2015. 
JARDIM, A.; YOSHIDA, C.; MACHADO FILHO, J. Política nacional, gestão e gerenciamento de resíduos sólidos. São Paulo: Manole, 2012.

LACERDA, L. Logística Reversa: uma visão sobre os conceitos básicos e as práticas operacionais, Revista Tecnologística, (Jan), p 46-50, 2002. Disponível em: <http://www.coppead.ufrj.br/pesquisa/cel/new/ fr-rev.htm.>. Acesso em: 08 nov. 2015.

LEITE, P. R. Logística reversa: meio ambiente e competitividade. 2ed. São Paulo: Pearson, 2009.

MARCONI, Marina de Andrade; LAKATOS, Eva Maria. Fundamentos de metodologia científica. 7. ed. São Paulo: Atlas, 2010.

MIGUEZ, E. C. Logística reversa como solução para o problema do lixo eletrônico: benefícios ambientais e financeiros. Rio de Janeiro: Qualitymark, 2012.

NATUME, R. Y.; SANT'ANNA, F. S. P. Resíduos eletroeletrônicos: um desafio para o desenvolvimento sustentável e a nova lei da política nacional de resíduos sólidos. In: INTERNATIONAL WORKSHOP ADVANCES IN CLEANER PRODUCTION, 3, 2011. São Paulo, 2011. Cleaner production initiatives and challenges for a sustainable world. São Paulo, 2011.

ONU BR NAÇÕES UNIDAS DO BRASIL. Brasil produziu 1,4 milhão de toneladas de resíduos eletrônicos em 2014, afirma novo relatório da ONU. 2015. Disponível em http://nacoesunidas.org/ brasil-produziu-14-milhao-de-toneladas-de-residuos-eletronicos-em-2014-afirma-novo-relatorio-da-onu/. Acesso em: 01 nov. 2015.

PEREIRA, A. L. et al. Logística reversa e sustentabilidade. São Paulo: Cengage, 2012.

SERVIÇO BRASILEIRO DE APOIO ÀS MICRO E PEQUENAS EMPRESAS SEBRAE- Cartilha Gestão Sustentável na Empresa. Cuiabá-MT, 2012. Disponível em:<,http://sustentabilidade.sebrae.com.br/ sustentabilidade/baixarArquivo?arquivo=e9bd203f95a27310 VgnVCM1000002af71eacRCRD> Acesso em 10. Abr. 2016

SUSLICK, S. B.; MACHADO, I. F; FERREIRA, D. F. Recursos minerais e sustentabilidade. Campinas, SP: Komedi, 2005.

TACHIZAWA, T.; FARIA, M. de S. Criação de novos negócios: gestão de micro e pequenas empresas. Rio de Janeiro, FGV, 2007. 


\section{DESAFIOS E OPORTUNIDADES DA LOGÍSTICA REVERSA \\ DE ELETROELETRÔNICOS EM UMA OPERADORA DE \\ CELULAR NA VISÃO DE GESTORES E USUÁRIOS}

TECHIN BRAZIL. Disponível em <https: //techinbrazil.com.br/ expansão-da-telefonia-móvel-no-brasil> Acesso em: 20 mar 2016.

TELECO - Inteligência em Telecomunicações LTE: Evolução das Redes Móveis. São Paulo, 2015. Disponível em: < http://www.teleco. com.br/ncel.asp>. Acesso em: 02 mar. 2016.

TELECO - Inteligência em Telecomunicações. Estatística de celulares no Brasil. São Paulo, 2015. Disponível em: < http://www.teleco.com. br/ncel.asp>. Acesso em: 02 mar. 2016.

TONANI, P. Responsabilidade decorrente da poluição por resíduos sólidos: de acordo com a Lei 12.305/2010 que institui a Política Nacional de Resíduos Sólidos. 2. ed. São Paulo: Método, 2011.

XAVIER, L. H.; CORRÊA, H. L.. Sistemas de logística reversa: criando cadeias de suprimentos sustentáveis. São Paulo: Atlas, 2013.

ZAMBON, B. P.; RICCO, A. S. Sustentabilidade Empresarial: uma oportunidade para novos negócios. Vitória-ES, 2009. Disponível em: $<$ http://www.craes.org.br/arquivo/artigoTecnico/Artigos_Sustentabilidade_Empresaria_Uma_oportunidade_para_novos_negciosl.pdf.>. Acesso em: 24 abr. 2016. 